Check for updates

Cite this: RSC Adv., 2019, 9, 26351

\title{
Polyvinylpyrrolidone/cellulose acetate electrospun composite nanofibres loaded by glycerine and garlic extract with in vitro antibacterial activity and release behaviour test $\uparrow$
}

\author{
Dhewa Edikresnha, (D) ab Tri Suciati, (D) ${ }^{c}$ Muhammad Miftahul Munir (D) *ab \\ and Khairurrijal Khairurrijal (D) *ab
}

The antibacterial activity of garlic (Allium sativum) is believed to be due to its organosulfur compounds, which can supposedly be used further in biomedical applications. This paper reported the use of electrospinning to encapsulate a garlic extract and glycerine in nanofibrous mats. Polyvinylpyrrolidone (PVP) and cellulose acetate (CA) were the building blocks of the composite fibres that served as the hydrophilic matrix to encapsulate the garlic extract with glycerine added mainly to improve the mechanical characteristics of the composite fibres. The combinations of the fibres were PVP/CA, PVP/ $\mathrm{CA} /$ garlic, PVP/CA/glycerine, and PVP/CA/glycerine/garlic. The characterizations included the morphology, chemical interaction, swelling degree, weight loss, acidity level, wettability, in vitro antibacterial test, and release behaviour test. The composite nanofibrous mats were uniform, bead-free with a size ranging from $350 \mathrm{~nm}$ to $900 \mathrm{~nm}$. The Fourier-transform infrared spectra proved the presence of the garlic extract and glycerine in the fibres. The swelling degree test showed that the fibrous mats generally did have maximum swelling degrees above 100\% except for the PVP/CA fibrous mat, whose maximum value was not achieved within 48 hours. The fibrous mat with glycerine showed generally larger weight loss compared to the fibrous mats without glycerine. The result of the contact angle measurement proved that the composite fibres are all hydrophilic with the PVP/CA/glycerine/garlic fibres being the least hydrophilic. The $\mathrm{pH}$ level of the fibre mats was from 3.7 to 4.0 due to the use of acetic acid. The Young's modulus and ultimate tensile strength of the mats were significantly reduced due to the presence of glycerine. The encapsulation of the garlic extract in the fibres did not eliminate the antibacterial activity of the garlic extract, as proven in the in vitro antibacterial test. The release of the garlic extract from the composite PVP/CA/glycerine/garlic fibres was found to be the largest due to the large diameter of the fibres, while the blend of PVP with CA successfully reduced the rate of release due to the insolubility of CA. We successfully encapsulated the garlic extract and glycerine in the PVP/CA nanofibrous mats with antibacterial activity.

Received 29th May 2019

Accepted 8th August 2019

DOI: $10.1039 / c 9 r a 04072 b$

rsc.li/rsc-advances garlic is due to its organosulfur compounds, which are soluble in both water and oil. ${ }^{6}$ Hence, garlic can be applied in a biomedical device to prevent bacterial growth. A garlic extractencapsulated nanofibrous matrix can hinder the bacterial growth physically and chemically. Since the bacterial size is usually at the microscale, it should not be able to penetrate the pores of the nanofibrous mats. ${ }^{7}$ Additionally, the growth of bacteria on the surface of the nanofibrous mats can be prevented chemically by the release of the encapsulated garlic extract from the fibres.

The antibacterial activity of garlic is assumed to come from the allicin compound in it, which has a different mechanism from other antibacterial agents such as silver, copper, and gold nanoparticles. Silver nanoparticles use physical means to destroy the bacteria by attaching themselves to the wall and \author{
Ganesa 10, Bandung 40132, Indonesia \\ $\dagger$ Electronic supplementary information (ESI) available. See DOI: \\ 10.1039/c9ra04072b \\ ${ }^{a}$ Department of Physics, Faculty of Mathematics and Natural Sciences, Institut \\ fi.itb.ac.id; krijal@fi.itb.ac.id; Fax: +62 22 86010051; Tel: +62 2286010050 \\ ${ }^{b}$ Research Center for Biosciences and Biotechnology, Institute for Research and \\ Community Services, Institut Teknologi Bandung, Jalan Ganesa 10, Bandung 40132, \\ Indonesia \\ 'Department of Pharmaceutics, School of Pharmacy, Institut Teknologi Bandung, Jalan
}


penetrate it. Additionally, silver nanoparticles create abundant free radicals and reactive oxygen species, thus preventing the growth of cells. ${ }^{8}$ Copper nanoparticles create reactive oxygen species in the bacterial cells, thus peroxidizing the cellular lipids, oxidizing proteins, and degrading DNA. ${ }^{9}$ Gold nanoparticles disrupt the membrane potential of the cell, thus weakening the metabolism of the cell. ${ }^{\mathbf{1 0}}$ On the other hand, allicin in garlic inhibits the thiol-containing enzymes such as cysteine proteinases, alcohol dehydrogenases, and thioredoxin reductases, which are important to sustain the metabolism and balance in microorganisms. ${ }^{11}$ However, the antibacterial activity degrades when stored at room temperature. ${ }^{12}$ Hence, a good encapsulant is needed.

In previous research, silver nanoparticles still maintained their antibacterial activity when encapsulated in polydopamine, a mussel-inspired chemical. ${ }^{13}$ In other reports, the release of silver nanoparticles from polydopamine was enhanced by involving graphene oxide ${ }^{14}$ or $\operatorname{MoS}_{2} \cdot{ }^{15}$ In a previous experiment, gold nanoparticles still possessed antibacterial activity against Staphylococcus aureus and Escherichia coli when encapsulated in polyurethane. ${ }^{\mathbf{1 6}}$ Additionally, copper nanoparticles coated with a polyurethane foam also exhibited antibacterial activity against Escherichia coli used in a water filter application. ${ }^{17}$ The results prove that the encapsulation of an antibacterial agent does not reduce the antibacterial activity itself.

In environmental and biomedical applications, many types of nanomaterials have been thoroughly researched with various strategies. Surface-modified $\mathrm{SiO}_{2}$ nanoparticles can adsorb the organic dye Congo red and hence can be used in wastewater treatment. ${ }^{18}$ Also, the dye adsorption capability of $\mathrm{MoS}_{2}$ can be significantly improved by surface modification with self-polymerized levodopa (DOPA). ${ }^{19}$ Other than dye adsorption, the removal of a metal ion such as $\mathrm{Cu}^{2+}$ is possible using a functionalized composite of carbon nanotubes. ${ }^{20}$ Additionally, the degradation of some pollutants can be catalysed by gold nanoparticles trapped inside a shell made of $\mathrm{Fe}_{3} \mathrm{O}_{4}$ polydopamine. ${ }^{21}$ Beside environmental applications, nanomaterial advancement also contributes to various biomedical fields, such as biomedical imaging, ${ }^{22-24}$ biosensing, ${ }^{24}$ cancer treatment, ${ }^{25}$ anti-diabetic materials, wound healing, ${ }^{26}$ and drug delivery. ${ }^{27-29}$ Hence, there is no limit to the types of nanomaterials that can be synthesized as well as their applications.

Recently, there has been a huge development in the application of electrospun nanofibres in the biomedical sector. The fibrous structure can sustain the migration and proliferation of the cells to allow tissue growth. ${ }^{30}$ Electrospun nanofibres have been widely applied in filtration, ${ }^{31,32}$ tissue culture, scaffolding, ${ }^{33}$ and drug carriers. ${ }^{34}$ Due to the large surface area of the nanofibres, a natural extract can be encapsulated and its stability is maintained within the polymer matrix. ${ }^{35}$ By adjusting its dimensions and morphology, the pharmaceutical aspects and pharmacokinetics of the encapsulated drug can be controlled. ${ }^{36}$

In many previous studies, it has been found that polyvinyl alcohol (PVA) has often been used as the building block of fibres since it has relatively good mechanical strength as well as excellent chemical resistance, hydrophilicity, and biocompatibility; therefore, it fits the requirements of biomedical applications. ${ }^{37}$ Nevertheless, PVA is not suitable as a carrier matrix for garlic extract since the dissolution of PVA requires a high temperature, while allicin present in the garlic extract is degraded at a temperature above $40{ }^{\circ} \mathrm{C} \cdot{ }^{38,39}$ Hence, the polymers used in this research were $\mathrm{PVP}^{40}$ and $\mathrm{CA}^{41}$ since they do not require a high temperature for dissolution. PVP is also non-toxic and biocompatible; hence, it is suitable for biomedical applications. ${ }^{42}$ Previously, PVP has been used as a carrier matrix for antibacterial agents such as cinnamon essential oil, ${ }^{43}$ cellulose nanocrystals/silver nanoparticles, ${ }^{44}$ quaternized chitosan derivatives, ${ }^{45}$ and the extract of Tecomella undulata. ${ }^{46}$ However, PVP can decompose rapidly when in contact with a humid environment, thus making it unsuitable for some biomedical applications such as wound dressing. ${ }^{47,48}$ To prevent rapid decomposition, it is then mixed with CA, which is waterinsoluble; hence, it will not degrade when in contact with water or a humid environment. CA is an ester of cellulose and acetic acid, which has been traditionally applied for lamination. ${ }^{49}$ In biomedical applications, CA has been used in tissue engineering, nutraceutical delivery, crop protection, cigarette filters, and antimicrobial mats. ${ }^{41}$ Similar to PVP, CA is also nontoxic and biocompatible. ${ }^{41,50}$ In previous reports, the blend of PVP/CA has been studied and successfully used as a carrier matrix for ibuprofen with acetone/DMAc as the solvent. ${ }^{51,52}$ However, the large Young's modulus of the blend composite nanofibres may limit the number of possible applications.

In this research, glycerine was used as an additive in the composite electrospun fibres although glycerine is not known to possess significant antibacterial activity. There is even a report stating that the incorporation of glycerine into isopropyl alcohol reduces the inhibition zone diameter of a substance. ${ }^{53}$ Another report also states that pure glycerine does not inhibit the growth of the Clostridium butyricum

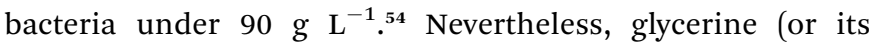
derivatives) can be used to improve the mechanical properties of a material such as increasing the ultimate tensile strength or the failure strain..$^{55}$ These properties are quite significant for certain applications such as for patients with cardiac conditions as a material that is too stiff can cause danger or discomfort. ${ }^{56}$ In general, more flexible materials, especially the biomaterials made of electrospun fibres, will have a broader range of applications, which is why glycerine is used.

Although it has been researched to a small extent in a previous paper, ${ }^{6}$ to the best of our knowledge, no detailed research has been conducted to further examine the characteristics of an electrospun composite fibrous mat with an encapsulated garlic extract and glycerine. Therefore, this research aimed to develop and characterize some properties of the composite fibres with an encapsulated garlic extract and added glycerine using conventional electrospinning in the blend of PVP and CA polymers. The characterizations involved a morphological examination by employing a scanning electron microscope, Fourier-transform infrared spectrometer, swelling degree/weight loss, contact angle measurement, mechanical tensile strength, antibacterial assay, and release behaviour test. 


\section{Experimental}

\subsection{Materials}

PVP with a molecular weight of $1300 \mathrm{~kg} \mathrm{~mol}^{-1}$ and CA with a molecular weight of $50 \mathrm{~kg} \mathrm{~mol}^{-1}$ were purchased from SigmaAldrich. The glycerine and glacial acetic acid used in this experiment were obtained from PT. Brataco, while distilled water was bought from the Department of Chemistry, ITB. Garlic was acquired from a local market, which was grown locally in West Java Province, Indonesia; it was stored at $4{ }^{\circ} \mathrm{C}$. Glacial acetic acid was mixed with water to make a $98 \%(\mathrm{v} / \mathrm{v})$ acetic acid solution.

\subsection{Extraction of garlic}

For the extraction process, garlic was firstly crushed by a blender machine until the texture became soft. The crushed garlic was then macerated in ethanol at a weight ratio of garlic to ethanol of $1: 1$ for two nights at an ambient temperature of $4{ }^{\circ} \mathrm{C}$. Afterward, the crushed garlic was centrifuged at $4600 \mathrm{rpm}$ for 30 minutes. The supernatant of the centrifuged garlic was then filtered using a qualitative filter paper of diameter $110 \mathrm{~mm}$ produced by Xinxing to filter any insoluble solid particles in the extract. This filtered liquid was then designated as the garlic extract used throughout the experiment. The extraction method was similar but with a slight modification to the previous experiment. ${ }^{57}$

\subsection{Precursor solutions}

The precursor solution was made firstly by dissolving each PVP and CA in 98\% acetic acid. The solutions of PVP and CA were made at the concentrations of $9 \mathrm{wt} \%$ and $9.6 \mathrm{wt} \%$, respectively. The CA solution was then mixed with PVP solution in the weight ratio of PVP : $\mathrm{CA}=8: 5$, which made the ratio of the dry weight of PVP to CA to be $3: 2$. The mixed solution was stirred at room temperature until it became fully homogenous. Subsequently, for every 13 grams of $\mathrm{PVP} / \mathrm{CA}$ solution, one gram of glycerine was added to produce the solution $\mathrm{PVP} / \mathrm{CA} /$ glycerine, or one gram of garlic extract was added to produce the solution PVP/ $\mathrm{CA} /$ garlic. The solution of PVP/CA/glycerine/garlic was made by adding both one gram of garlic extract and one gram of glycerine to the PVP/CA solution. Therefore, there were four precursor solutions produced in this study; they were PVP/CA, $\mathrm{PVP} / \mathrm{CA} /$ garlic, $\mathrm{PVP} / \mathrm{CA} /$ glycerine, and PVP/CA/glycerine/garlic.

\subsection{Characterizations of solution properties}

Before undergoing the electrospinning process, glycerine, garlic extract, and all precursor solutions were characterized for their viscosity using an Ostwald-Fenske viscometer (Fisher Scientific, Surface Tensiomat model 21); the conductivity was determined using a conductometer (Mettler Toledo AG, 8603 Schwerzenbach), and the surface tension was measured using a du Nöuy tensiometer (Fisher Scientific, 50 A643).

\subsection{Electrospinning process}

The precursor solution was inserted into a syringe equipped with a $21 \mathrm{G}$ needle with an inner diameter of $0.80 \mathrm{~mm}$. After everything was set in place, the electrospinning process took place (Nachriebe, Nachriebe 601) (Fig. 1). The electrospinning apparatus is the same as that used in a previous experiment. ${ }^{32}$ The solutions $\mathrm{PVP} / \mathrm{CA}, \mathrm{PVP} / \mathrm{CA} /$ garlic $\mathrm{PVP} / \mathrm{CA} /$ glycerine, and $\mathrm{PVP} / \mathrm{CA} /$ garlic/glycerine were electrospun at an applied voltage of $15 \mathrm{kV}$, flow rate of $10 \mu \mathrm{L}$ per minute, and gap distance of $12 \mathrm{~cm}$. The environmental parameters including the relative humidity and temperature of the electrospinning chamber were kept at $50-60 \%$ and $25{ }^{\circ} \mathrm{C}$, respectively.

\subsection{Scanning electron microscopy and Fourier-transform infrared spectroscopy}

The morphology and diameter of the fibres were investigated by analyzing the images taken from a scanning electron microscope (SEM) (JEOL, JSM-6360LA) with the excitation voltage of $15 \mathrm{kV}$. The existing functional groups and the intermolecular interaction in the composite fibrous mats were identified by a Fourier-transform infrared (FTIR) spectrometer (Bruker, Alpha) in the wavenumber range from 500 to $4500 \mathrm{~cm}^{-1}$.

\subsection{Wettability test}

To examine the wettability of the fibrous mats, a contact angle test was performed at room temperature using a contact angle meter (Nachriebe, Nachriebe 320), which is similar to the apparatus in a previous research. ${ }^{32}$ A $5 \mu \mathrm{L}$ water droplet was dropped on the mat under testing (MUT), whose shape was expected to be flatter with time due to the hydrophilicity of the fibrous mats. The image of the water droplet on the surface of the MUT was then captured and analyzed.

\subsection{Swelling degree/weight loss test}

The swelling degree of the fibrous mats was examined by placing the fibrous mats inside a phosphate buffer saline (PBS) solution at the physiological pH of 7.4 at approximately $37^{\circ} \mathrm{C}$. The weight of the mats was then measured at $0,3,6,12,24$, and 48 hours. Before weighing, the fibrous mats were blotted onto a filter paper to absorb the water left on the surface of the mats.

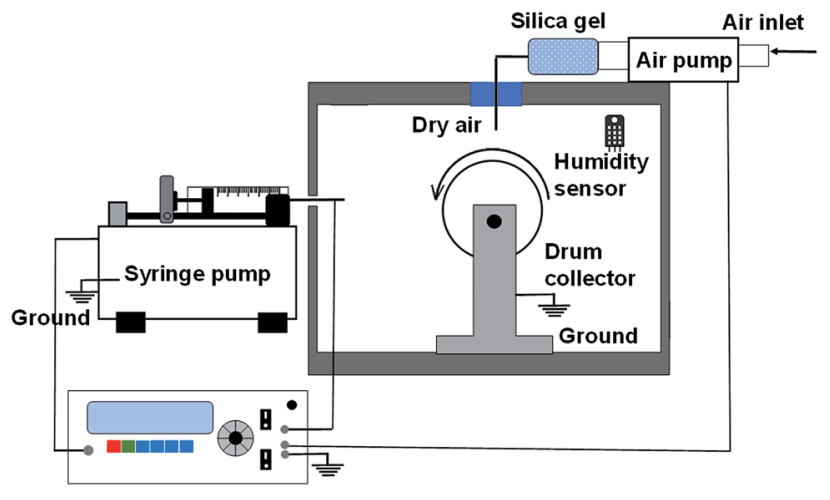

Fig. 1 Schematic diagram of the electrospinning apparatus. 
The swelling degree of the fibrous mats could then be determined from the following eqn (1):

$$
\text { Degree of swelling }(\%)=\left[\frac{M_{t}-M_{\mathrm{i}}}{M_{\mathrm{i}}}\right] \times 100
$$

here, $M_{t}$ is the weight of the fibrous mat after $t$ hours of soaking and $M_{\mathrm{i}}$ is the initial mass.

The weight loss test of the mats is basically complementary to the swelling degree test. The soaked fibres were warmed in an oven set at $40{ }^{\circ} \mathrm{C}$ until a constant weight was achieved. The weight loss could be determined from eqn (2):

$$
\text { Weight loss }(\%)=\left[\frac{M_{\mathrm{i}}-M_{\mathrm{d}}}{M_{\mathrm{i}}}\right] \times 100
$$

here, $M_{\mathrm{d}}$ is the weight of the dried mats after immersion in PBS for $t$ hours, while $M_{\mathrm{i}}$ is the initial weight of the mats before being soaked in water. ${ }^{6}$

\subsection{Tensile test}

The tensile strength and Young's modulus of the mats were also investigated by conducting a tensile test on all the fibrous mats. The measurements were carried out using a tensile tester apparatus (Textechno, Favigraph). The mats were cut into rectangular shapes with the dimensions of $2.5 \mathrm{~mm} \times 25 \mathrm{~mm}$ and the thickness was measured by a screw micrometer. The cross-sectional area of the rectangular cuts was needed to determine the stress of the mats. Young's modulus is the slope of the linear part of the stress-strain curve, while the ultimate tensile strength is the maximum stress on the curve. The load cell was $100 \mathrm{cN}$, the extension rate was $0.6 \mathrm{~mm} \mathrm{~min}^{-1}$, and the gauge length was $10 \mathrm{~mm}$. The test was conducted in triplicate. The extension rate and the gauge length were similar to that in a previous experiment. ${ }^{44}$

\subsection{0 pH test}

The $\mathrm{pH}$ level was examined to determine the level of acidity of the fibrous mat. The $\mathrm{pH}$ level of the composite nanofibrous mats was investigated using a pH meter (Mettler-Toledo, FE20Kit). About $100 \mathrm{mg}$ fibrous mats were stirred for three hours in ten $\mathrm{mL}$ deionized water. This method is similar to a previous experiment. $^{58}$

\subsection{In vitro antibacterial test}

The antibacterial activity of the garlic extract and the composite nanofibrous mats was investigated against Staphylococcus aureus (ATCC 6538) and Pseudomonas aeruginosa (ATCC 9027). The antibacterial activity of the garlic extract was examined using the microdilution method, while the antibacterial activity of the composite nanofibrous mats was inspected using the disk diffusion method based on the Clinical Standard Laboratory Institute method. ${ }^{59,60}$ The antibacterial test of the garlic extract was conducted in a 96-well microtiter plate, in which the minimum inhibitory concentration (MIC) and minimum bactericidal concentration (MBC) were to be determined. The plate consisted of 96 wells with twelve columns (labeled 1-12) and eight rows (labeled A-H). The wells in rows A to C were reserved for Pseudomonas aeruginosa, while the wells in rows F to $\mathrm{H}$ were used for Staphylococcus aureus. The wells in column 1 were filled with $200 \mu \mathrm{L}$ Mueller-Hinton broth (MHB) medium, while the wells from column 2 to column 11 were filled with 100 $\mu \mathrm{L}$ MHB medium. The wells in column 12 were initially filled with $200 \mu \mathrm{L}$ garlic extract solution. Afterwards, one hundred $\mu \mathrm{L}$ of garlic extract from column 12 was taken and mixed with the MHB in the eleventh column. Then, one hundred $\mu \mathrm{L}$ of the mixed solution of garlic extract and MHB in the eleventh column was again taken and mixed with the MHB in the tenth column. The procedure was repeated until the third column. Therefore, the concentrations of the garlic extract in MHB (v/v) from the twelfth column to the third column were $100 \%, 50 \%$, $25 \%, 12.5 \%, 6.25 \%, 3.125 \%, 1.56 \%, 0.78 \%, 0.39 \%$, and $0.195 \%$. Subsequently, $10 \mu \mathrm{L}$ of the bacterial suspension was added and mixed in each well from column 2 to 12 . In this test, column 2 functioned as the positive control for all the samples, where there was only the growth medium and the bacteria. Therefore, the growth of the bacteria was expected in column 2. On the other hand, column 1 served as the negative control, where there was only the growth medium inside. The microtiter plate was subsequently incubated aerobically for 24 hours at $37^{\circ} \mathrm{C}$. The MIC of garlic extract was determined from the well in which the visible growth of bacteria was totally inhibited after incubation. After observation, the solution from each well was swabbed onto a Mueller-Hinton agar (MHA) plate and incubated for another 24 hours. The MBC of the garlic extract was determined from the lowest concentration of garlic extract at which no visible growth occurred on the swabbed plates.

To investigate the antibacterial activity of the composite nanofibrous mats, each mat was cut into a circle with a diameter of about $2 \mathrm{~cm}$. The mass of the circular mats varied due to the different components in the mat. All the mats were irradiated under UV light for 20 minutes for sterilization. Each circle was placed on top of the MHA solid in a Petri dish. The inoculum of Staphylococcus aureus $\left(1.3 \times 10^{6} \mathrm{cfu} \mathrm{mL}^{-1}\right)$ and Pseudomonas aeruginosa $\left(4.5 \times 10^{5} \mathrm{cfu} \mathrm{mL}^{-1}\right)$ was mixed with MHA and then subsequently poured on top of the circular mat. Afterwards, the samples were incubated for 24 hours at $37^{\circ} \mathrm{C}$. After 24 hours of incubation, $10 \mu \mathrm{L}$ agar from the top of the circular mat was diluted in sodium chloride solution several times to obtain a calculated concentration of bacteria. Next, one $\mathrm{mL}$ of the diluted bacterial suspension was swabbed on MHA in a Petri dish and then incubated for 24 hours at $37^{\circ} \mathrm{C}$. After the second incubation, the number of bacterial colonies was counted to determine the activity of bacterial growth inhibition. The samples used in this test were the composite mats of $\mathrm{PVP} / \mathrm{CA}, \mathrm{PVP} / \mathrm{CA} /$ glycerine, $\mathrm{PVP} / \mathrm{CA} /$ garlic, and $\mathrm{PVP} / \mathrm{CA} /$ glycerine/garlic. As a positive control, the number of bacterial colonies in the MHA without any composite nanofibrous mat was also counted. The antibacterial activity of the fibrous mat specific to its mass was determined through eqn (3):

Antibacterial activity

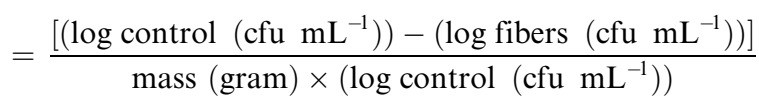


The $\log _{10}$ reduction over the unit of area $\left(\mathrm{cm}^{2}\right)$ of the bacterial colony was found through eqn (4):

Antibacterial activity

$$
=\frac{\left[\left(\log \text { control }\left(\mathrm{cfu} \mathrm{mL} \mathrm{m}^{-1}\right)\right)-\left(\log \text { fibers }\left(\mathrm{cfu} \mathrm{mL}^{-1}\right)\right)\right]}{\text { area of membrane }\left(\mathrm{cm}^{2}\right)}
$$

\subsection{Release test}

Before conducting the release test, glycerine and the garlic extract were calibrated first using a UV-Visible spectrophotometer (Beckman Coulter, DU 7500i). The garlic extract was diluted in PBS at the physiologic pH of 7.4 and a peak occurred at $203 \mathrm{~nm}$. On the other hand, glycerine was diluted in $0.1 \mathrm{M}$ $\mathrm{NaOH}$ in PBS at pH 7.4 since no peak occurred when only PBS at pH 7.4 was used. The peak for glycerine appeared at $217 \mathrm{~nm}$ when diluted in $0.1 \mathrm{M} \mathrm{NaOH}$ in PBS at $\mathrm{pH} 7.4 .^{61}$ The calibration curve is needed to determine the concentration of garlic extract and glycerine in the solution. Afterwards, the maximum content of garlic and glycerine in the fibrous mat was determined. The weighed fibrous mat was stirred in a magnetic stirrer filled with the corresponding solutions until it was fully dispersed. The solution was then scanned using the UV-Visible spectrophotometer. The total content of garlic and glycerine could be determined from the calibration curve and the absorbance.

After determining the total content of garlic and glycerine, the release profiles of garlic extract and glycerine were examined using a paddle dissolution test apparatus (Hanson Research, SR8 Plus). The rotational speed of the paddle was $50 \mathrm{rpm}$ and the temperature was maintained at $37{ }^{\circ} \mathrm{C} \pm 0.5^{\circ} \mathrm{C}$. The release of garlic was obtained from the $\mathrm{PVP} / \mathrm{CA} /$ glycerine/garlic and $\mathrm{PVP} / \mathrm{CA} /$ garlic fibrous mats, while glycerine was released from the $\mathrm{PVP} / \mathrm{CA} /$ glycerine/garlic and $\mathrm{PVP} / \mathrm{CA} /$ glycerine fibrous mats. The release study of garlic was conducted at $400 \mathrm{~mL}$ of PBS at the physiological $\mathrm{pH}$ of 7.4, while the solution for the release of glycerine was $0.1 \mathrm{M} \mathrm{NaOH}$ in PBS at pH 7.4. Each slice of the nanofibrous mat was weighed and added into PBS. At 5, 10, 15, $30,45,60$, and 120 minutes, a solution of approximately $5 \mathrm{~mL}$ was taken out and the medium was substituted by an equal amount of the buffer solution. The amount of garlic and glycerine released at the mentioned intervals of time was measured by using the UV-Visible spectrophotometer at $203 \mathrm{~nm}$ for garlic and at $217 \mathrm{~nm}$ for glycerine. The method was similar to the previous experiments. ${ }^{47,62}$

\section{Results and discussion}

\subsection{Solution properties}

As listed in Table 1, the composition of the precursor solutions affects the density, viscosity, surface tension, and conductivity of solutions. Glycerine is known to have large viscosity and surface tension since it contains three hydroxyl groups; hence, the intermolecular forces will be greater due to many hydrogen bonds within a single molecule. The result obtained in this experiment did not differ much from that of a previous experiment. ${ }^{63}$ The garlic extract, on the other hand, has very low viscosity since it is an ethanol-mixed solution with some oily garlic compounds. Hence, a solution system containing glycerine has significantly larger viscosity than the solution without glycerine. Meanwhile, the conductivity of the garlic extract is significantly large, which may be due to the organosulfur compounds of garlic as sulphur generally has large conductivity. ${ }^{64}$ Consequently, the solution systems containing garlic extract have significantly larger conductivity than the solutions without the extract. Lastly, the surface tension of glycerine is relatively high albeit numerically not as significant as the other two properties, but it matches quite well with that observed in a previous experiment. ${ }^{65}$ The surface tension of the garlic extract itself, although macerated by the mixed solvents of ethanolwater, seemed to be affected by the essential oils of garlic as the surface tension is found to be much lower than the surface tension of water. ${ }^{66}$

\subsection{SEM images}

SEM images were taken to examine the morphological characteristics of the mats. The morphology of the electrospinning products usually appears in the form of fine fibres, beaded fibres, or simple beads. In this study, the morphology of the fibres was investigated for the fibres made from different precursor solutions (Fig. 2). The homogeneity of the fibres was investigated by calculating the coefficient of variance (CV) of the fibres, which is defined as the ratio of the standard deviation over the average diameter. Homogenous fibres have CV smaller than 0.3 , with a lesser CV number indicating a larger degree of homogeneity. ${ }^{67}$ The composite fibrous mat built up from pure polymers (PVP/CA) was the most uniform with CV of 0.10, followed by the fibrous mats made from PVP/CA/garlic (0.19), PVP/ $\mathrm{CA} /$ glycerine/garlic (0.22), and lastly $\mathrm{PVP} / \mathrm{CA} /$ glycerine/garlic/ glycerine (0.23). As the polymer is the building block of the fibres, the existence of non-polymeric substances usually reduces the homogeneity of the fibres, as seen in the case of the composite fibres with glycerine and garlic extract. ${ }^{68}$ Since glycerine served as the plasticizer of the fibrous mats, the fibres tend to be sticky. Furthermore, the fibres with glycerine have a certain amount of branches and the edge of one fibre cannot be differentiated clearly from that of another fibre, as also found in a previous research. ${ }^{6}$ This condition leads to the situation where the fibres seem to be collected in a cluster with the branches of the fibres coming out from the knot (Fig. 2c and d).

The fibres made from PVP/CA/glycerine/garlic exhibited the largest diameter since the precursor solution showed the largest viscosity. For the precursor solution with large viscosity, it is more difficult for the electrical force to stretch the jet; hence, the fibres generally have a larger diameter. ${ }^{69}$ Also, it appeared that conductivity did play a role in the size determination of the electrospun fibres. The solutions of $\mathrm{PVP} / \mathrm{CA}$ and $\mathrm{PVP} / \mathrm{CA} /$ garlic did not differ much in their viscosities, and the PVP/CA solution had slightly less viscosity. The precursor solution of PVP/ CA/garlic, however, had much greater conductivity. Therefore, the average diameter of $\mathrm{PVP} / \mathrm{CA} /$ garlic was significantly less as compared to that of the fibres of PVP/CA. Conductivity is related 
Table 1 The characteristics of the precursor solutions

\begin{tabular}{|c|c|c|c|c|c|}
\hline No. & Name of solution & Density $\left(g \mathrm{~mL}^{-1}\right)$ & Viscosity (centipoise) & $\begin{array}{l}\text { Conductivity at } \\
25{ }^{\circ} \mathrm{C}\left(\mu \mathrm{S} \mathrm{cm}^{-1}\right)\end{array}$ & $\begin{array}{l}\text { Surface tension } \\
\text { (dyne per } \mathrm{cm} \text { ) }\end{array}$ \\
\hline 1 & Glycerine & 1.26 & $927.47 \pm 0.47$ & $0.78 \pm 0.01$ & $62.50 \pm 0.10$ \\
\hline 3 & $\mathrm{PVP} / \mathrm{CA}$ & 0.93 & $354.69 \pm 0.27$ & $8.76 \pm 0.01$ & $36.73 \pm 0.15$ \\
\hline 4 & PVP/CA/garlic & 0.94 & $356.91 \pm 0.01$ & $60.20 \pm 0.01$ & $35.03 \pm 0.06$ \\
\hline 5 & PVP/CA/glycerine & 0.94 & $496.80 \pm 0.06$ & $16.48 \pm 0.01$ & $38.20 \pm 0.20$ \\
\hline
\end{tabular}
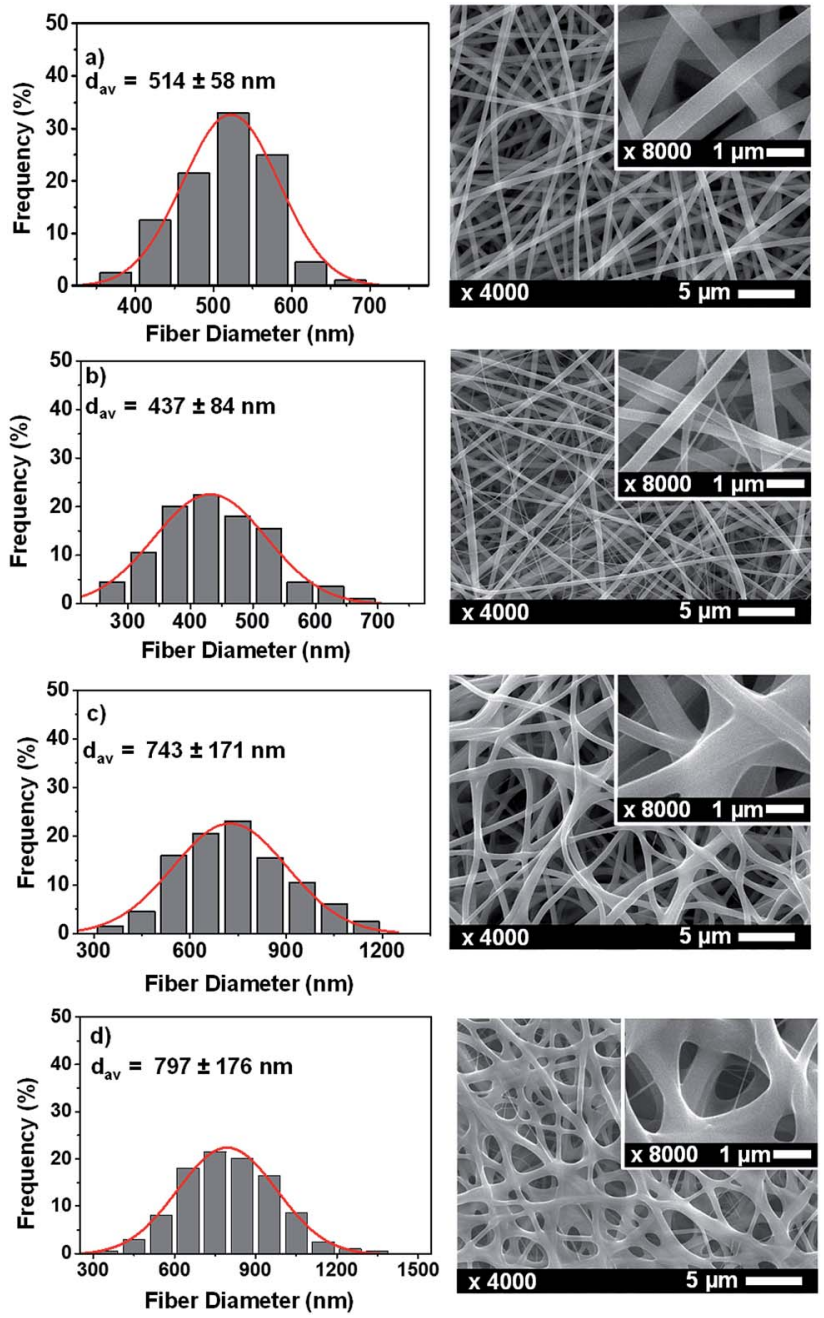

Fig. 2 The size distribution of the fibres and the SEM images of the fibres made from the solutions of (a) PVP/CA, (b) PVP/CA/garlic, (c) $\mathrm{PVP/CA} /$ glycerine, and (d) PVP/CA/glycerine/garlic.

to the number of induced charges in a solution when a high voltage is applied. Higher conductivity leads to a larger number of charges; hence, the electrical force becomes larger and the diameter becomes smaller. ${ }^{70}$ The effect of conductivity, nevertheless, was less profound than the effect of viscosity as the significantly larger conductivity of $\mathrm{PVP} / \mathrm{CA} /$ glycerine/garlic compared to that of $\mathrm{PVP} / \mathrm{CA} /$ glycerine did not prevent the latter from having a smaller diameter.
Based on the empirical result of a previous study reported by Munir et al., the viscosity and the conductivity of the PVP/CA/ garlic solution far exceeded the minimum number to form smooth and bead-free fibres..$^{71}$ Hence, no beads were found, as observed in the SEM images.

\subsection{FTIR spectra}

FTIR analysis was conducted to observe the functional groups of the composite fibres affected by the presence of the garlic extract and glycerine in the electrospun composite nanofibrous mats (Fig. S1†). The peaks for the PVP powder were found at $3448,2954,1660,1430$, and $1290 \mathrm{~cm}^{-1}$. The PVP powder was characterized by the peaks at 1660,1430 , and $1290 \mathrm{~cm}^{-1}$, which were attributed to $\mathrm{C}=\mathrm{O}$ stretching, asymmetric stretching of $\mathrm{C}-\mathrm{H}$ deformations, and $\mathrm{C}-\mathrm{N}$ stretching, respectively, for the pyrrolidone rings. The broad peak at $3448 \mathrm{~cm}^{-1}$ was due to the hygroscopic nature of PVP as it can form hydrogen bonds with the $\mathrm{C}=\mathrm{O}$ groups in a humid environment. The peak at $2954 \mathrm{~cm}^{-1}$ represents the asymmetric stretching of $\mathrm{CH}_{2}$ deformation. ${ }^{40}$

The spectrum of cellulose acetate powder shows a widening peak located around $3487 \mathrm{~cm}^{-1}$, indicating the stretching of $\mathrm{O}-\mathrm{H}$ in unacetylated cellulose, while the peak at $1751 \mathrm{~cm}^{-1}$ is attributed to the stretching of $\mathrm{C}=\mathrm{O}$ in the acetyl group. The bending vibration of $\mathrm{C}-\mathrm{H}$ of $\mathrm{CH}_{3}$ in the acetyl group is shown by the peak at $1377 \mathrm{~cm}^{-1}$. The peaks at 1236 and $1039 \mathrm{~cm}^{-1}$ represent the stretching of $\mathrm{C}-\mathrm{O}$ in the acetyl group and the stretching vibration of $\mathrm{C}-\mathrm{O}-\mathrm{C}$ from the cellulose backbone. ${ }^{72}$

The FTIR spectrum of glycerine shows a broad peak around $3414 \mathrm{~cm}^{-1}$, indicating the stretching mode of $\mathrm{O}-\mathrm{H}$. The peaks at 2937 and $2883 \mathrm{~cm}^{-1}$ prove the existence of the asymmetrical and symmetrical stretching modes of $\mathrm{CH}_{2}$, respectively. The peak at $1413 \mathrm{~cm}^{-1}$ indicates the bending vibration of $\mathrm{CH}_{2}$. The sharp peak at $1043 \mathrm{~cm}^{-1}$ is related to the $\mathrm{C}-\mathrm{O}$ stretching, while the $\mathrm{C}-\mathrm{O}-\mathrm{H}$ stretching is represented by the peak at $924 \mathrm{~cm}^{-1}{ }^{73}$

The FTIR spectrum of the liquid garlic extract has a similar peak to the other results, which is a broad peak appearing at $3415 \mathrm{~cm}^{-1}$. This peak represents the stretching vibration of $\mathrm{O}-\mathrm{H}$ from the hydroxyl group, which indicates the presence of polyhydroxy compounds, including flavonoids, non-flavonoids, and saponins. These compounds are responsible for the antioxidant activity of garlic or any plant in general. The peak at $2951 \mathrm{~cm}^{-1}$ is related to the asymmetric stretching of C-H in the aromatic compounds. The peak at $1643 \mathrm{~cm}^{-1}$ represents the 
stretching of $\mathrm{C}=\mathrm{O}$ from the carbonyl and carboxylate groups, while the peak at $1406 \mathrm{~cm}^{-1}$ is due to the bending vibrations of $\mathrm{O}-\mathrm{H}$ in carboxylic acids, which indicate the presence of flavonoids, tannins, saponins, and glycosides. Tannins, saponins, and glycosides are known to be responsible for the antibacterial activity of extracts. The sharp peak at $1016 \mathrm{~cm}^{-1}$ is the characteristic peak of a garlic extract, which indicates the $S=0$ group and proves the existence of organosulfur compounds such as alliin, allicin, and diallyl disulfide. ${ }^{74}$

The existence of the components in the composite fibres was confirmed (Fig. 3). The characteristic peaks for PVP are represented by the peaks at 1662,1425 , and $1290 \mathrm{~cm}^{-1}$ for the composite PVP/CA fibres, by the peaks at 1664, 1438, and $1292 \mathrm{~cm}^{-1}$ for the composite PVP/CA/garlic fibres, by the peaks at 1662,1438 , and $1292 \mathrm{~cm}^{-1}$ for the composite PVP/CA/glycerine fibres, and by the peaks at 1662,1435 , and $1294 \mathrm{~cm}^{-1}$ for the composite $\mathrm{PVP} / \mathrm{CA} /$ glycerine/garlic fibres. The characteristics peaks of CA (1751 and $1377 \mathrm{~cm}^{-1}$ ) were observed for all the composite fibres at almost identical wavenumbers. The characteristic peaks are indicated by the wavenumbers 1751 and $1371 \mathrm{~cm}^{-1}$ for the composite PVP/CA fibres, wavenumbers 1753 and $1371 \mathrm{~cm}^{-1}$ for the composite PVP/CA/garlic fibres, wavenumbers 1751 and $1373 \mathrm{~cm}^{-1}$ for the composite PVP/CA/ glycerine fibres, and wavenumbers 1751 and $1373 \mathrm{~cm}^{-1}$ for the composite $\mathrm{PVP} / \mathrm{CA} /$ glycerine/garlic fibres. The characteristics peaks of glycerine (1043 and $924 \mathrm{~cm}^{-1}$ ) were observed for both

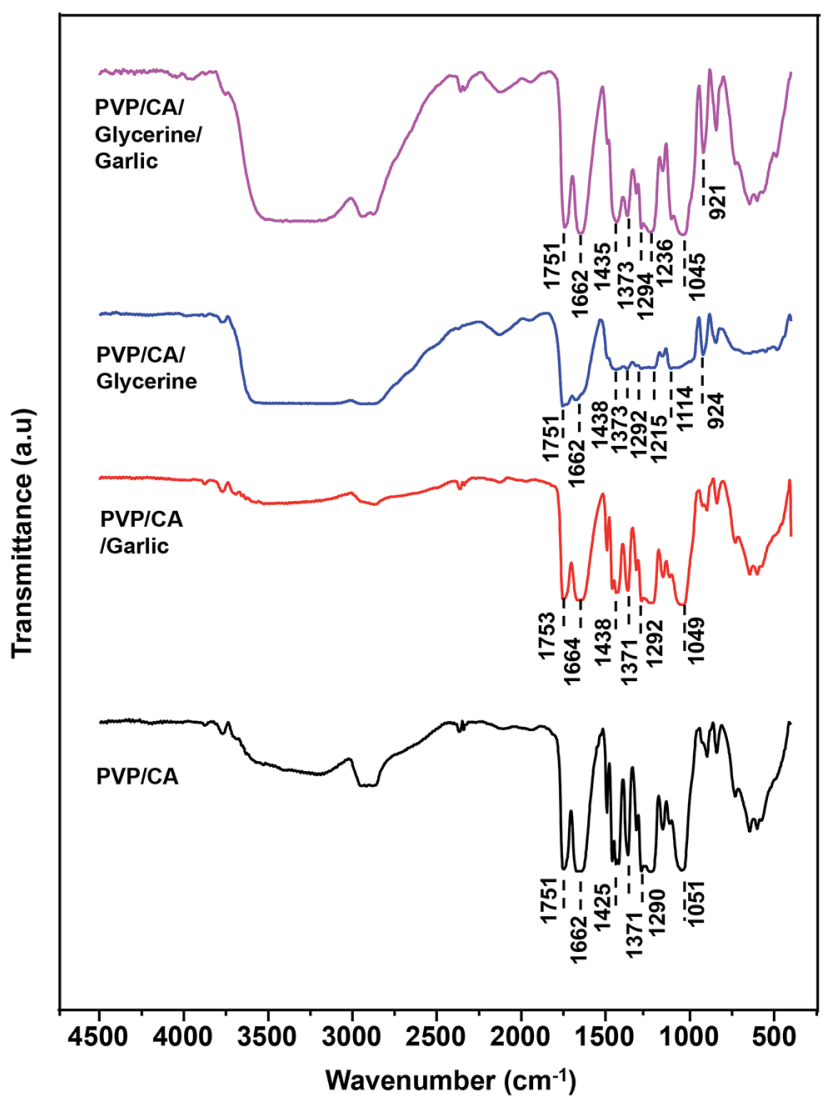

Fig. 3 FTIR spectra of the composite fibres.
$\mathrm{PVP} / \mathrm{CA} /$ glycerine (at 1114 and $924 \mathrm{~cm}^{-1}$ ) and PVP/CA/glycerine/ garlic (at 1045 and $921 \mathrm{~cm}^{-1}$ ). Lastly, the characteristic peak for the garlic extract was found at $1049 \mathrm{~cm}^{-1}$ for $\mathrm{PVP} / \mathrm{CA} /$ garlic, while it coincided with the peak for glycerine at $1045 \mathrm{~cm}^{-1}$ for PVP/CA/ glycerine/garlic, forming a shoulder beside the sharp peak. Therefore, it can be concluded that the garlic extract and glycerine were well included in the composite fibres.

\subsection{Swelling degree/weight loss}

The investigation of the swelling degree is important for certain applications in biomedicine. For example, it is useful to predict whether a mat is capable of absorbing the exudate of the wound. ${ }^{6}$ A careful examination of the degree of swelling showed that each fibrous mat generally did have maximum swelling before being reduced again (Fig. 4). The exception was the fibrous mat of $\mathrm{PVP} / \mathrm{CA}$ as the maximum point of swelling was not reached within 48 hours, and the swelling degree was about $800 \%$ after 48 hours. In general, the maximum swelling degree of the composite fibres was high (all of them were above 100\%) due to the hydrophilic nature of the carrier matrices, PVP, and CA. During immersion, the fibrous mat absorbed the PBS liquid; thus, it was swollen up until a certain degree. Afterwards, the fibres started to disintegrate in the liquid, making them not in one full piece as before; hence, there was a decrease in the weight, which was also observed in a previous study. ${ }^{75}$ The addition of glycerine into the fibres significantly lowered the maximum degree of swelling, where the degree of swelling was $120 \%$ in the case of PVP/CA/glycerine fibres and $170 \%$ for the $\mathrm{PVP} / \mathrm{CA} /$ garlic/glycerine fibres. Glycerine filled in the voids between the fibres, decreasing the porosity of the fibrous mat and reducing the contact area between the fibres and the water; hence, less absorption of liquids occurred, as can be observed from the SEM images. Additionally, the adhesive characteristics of glycerine also contributed to the low swelling degree of the fibrous mat since it hampers the intermolecular motion and the extrication of PVP/CA chains. ${ }^{6}$ When the garlic extract was added into the fibrous mat of PVP/CA, the maximum swelling

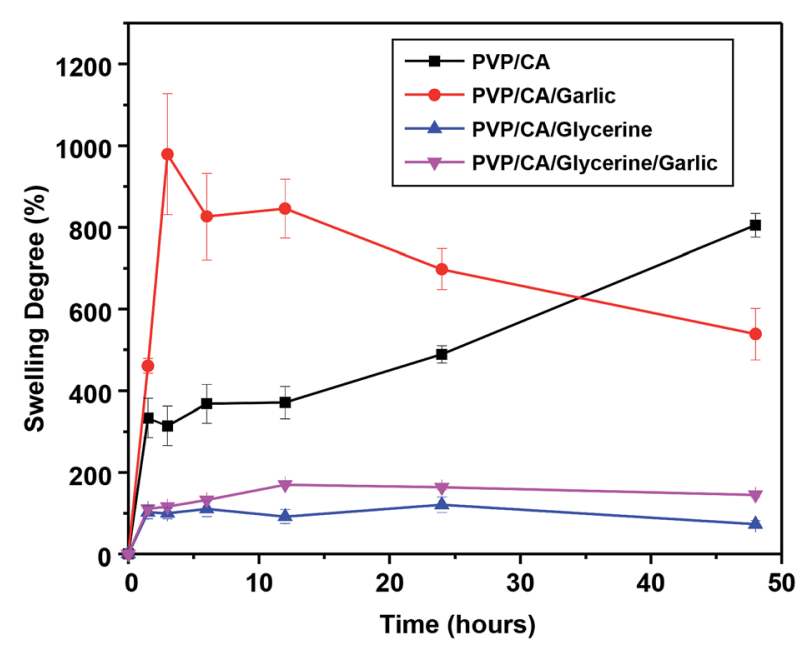

Fig. 4 The swelling degree of the composite fibrous mats. 
degree was near $1000 \%$ after one and a half hours of immersion, after which the degree of swelling decreased rapidly. According to this study alone, PVP/CA/garlic and PVP/CA/glycerine/garlic are expected to be able to absorb body liquids without any problem, and they are suitable for some biomedical applications such as wound dressing.

The weight loss experiment confirmed that a longer duration of immersion increased the weight loss of the fibres, which was expected since more fibres were dissolved (Fig. 5). However, the fibres with glycerine generally show a larger weight loss compared to the fibres without glycerine. It was expected that glycerine was lost during the evaporation of the wet fibres. The fibres without glycerine, on the other hand, did not have any glycerine from the beginning. Therefore, the percentage of loss was smaller. The garlic extract did not show any significant effect on the weight loss and it was expected that the extract molecules formed bonds with the polymer molecules.

\subsection{Wettability test}

The wettability of the surface of the fibrous mat must be investigated to examine how the mat interacts with water droplets in a humid environment. A hydrophilic mat will easily absorb the water droplets, causing the mat to decay. Conversely, a hydrophobic mat does not experience any decay during the interaction with water droplets and no wetting occurs on the surface. ${ }^{32}$ The contact angles for the mats of PVP/CA/garlic, PVP/ $\mathrm{CA} /$ glycerine, $\mathrm{PVP} / \mathrm{CA} /$ glycerine/garlic, and $\mathrm{PVP} / \mathrm{CA}$ and also the images of a water droplet resting on the surface of each mat were recorded (Fig. 6). The contact angles for PVP/CA/garlic, $\mathrm{PVP} / \mathrm{CA} /$ glycerine, $\mathrm{PVP} / \mathrm{CA} /$ glycerine/garlic, and PVP/CA mats were $10.94^{\circ}, 29.72^{\circ}, 69.19^{\circ}$, and $13.75^{\circ}$, respectively. For all the mats, the contact angle was found to be under $90^{\circ}$, hence proving that all the mats are hydrophilic (note: the contact angle of a hydrophobic surface will be larger than $\left.90^{\circ}\right) .{ }^{76}$ The low contact angles were predictable since the backbone of the fibrous mats was made up of polyvinylpyrrolidone and cellulose

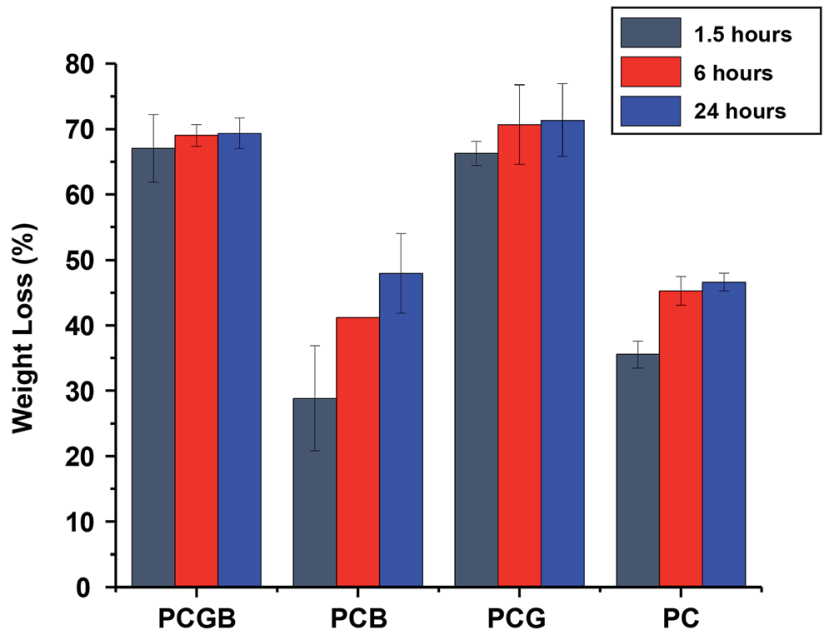

Fig. 5 The weight loss of the fibres composed of, from left to right, $\mathrm{PVP} / \mathrm{CA} /$ glycerine/garlic extract, PVP/CA/garlic, PVP/CA/glycerine, and PVP/CA.

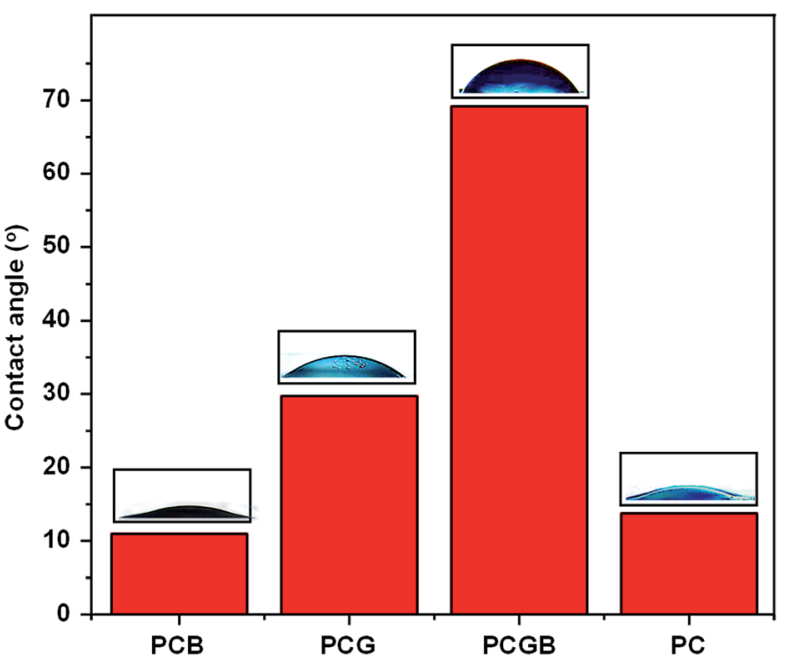

Fig. 6 The contact angle with its respective sessile drop pictures for (from left to right) PVP/CA/garlic, PVP/CA/glycerine, PVP/CA/glycerine/garlic, and PVP/CA.

acetate, both of which are hydrophilic. ${ }^{77}$ It is worth mentioning that there were different degrees of hydrophilicity among the mats. It is highly likely that the wettability of the fibres is closely related to the average diameter of the fibres. PVP/CA/garlic, which exhibited the smallest average diameter, showed the lowest contact angle. Conversely, the PVP/CA/glycerine/garlic mat exhibited the largest contact angle. Since the mat was very hydrophilic, the lower diameter indicated a larger total surface area between the fibres; hence, there was more contact between the droplet and the mat, making it more hydrophilic. Compared to a previous experiment, some measured contact angles of the materials used for biomedical applications were found to be between $54^{\circ}$ (alginate) and $90^{\circ}$ (polyethylene terephthalate). ${ }^{78}$

\section{$3.6 \mathrm{pH}$ level of mats}

The investigation of the $\mathrm{pH}$ level of the mats is important since there is a tolerable range of $\mathrm{pH}$ in which the mats can be used for biomedical applications. The growth of bacteria is rapid when the $\mathrm{pH}$ is above 6.0. Therefore, the $\mathrm{pH}$ of the mats should be low to hinder the growth of bacteria. However, a very acidic mat may have limited applications. As such, healthy skin has a pH between 4.0 and 6.0 and thus, the aim should be to obtain mats with $\mathrm{pH}$ within the same range. ${ }^{79}$ In this experiment, the acidity levels of the mat, glycerine liquid, deionized water, and garlic extract are shown in Table 2 .

As expected, the $\mathrm{PVP} / \mathrm{CA}$ mat has the lowest $\mathrm{pH}$ or, in other words, it is the most acidic, while the PVP/CA/glycerine/garlic mat has the highest $\mathrm{pH}$ since the $\mathrm{pH}$ value of acetic acid as the solvent of the precursor solution is very low, which is about 2.4. ${ }^{80}$ The PVP/CA mat was synthesized from a precursor solution with the least concentration of the solute; hence, the content of acetic acid as the solvent was the largest, while the opposite case was observed for PVP/CA/glycerine/garlic. The $\mathrm{pH}$ values of the $\mathrm{PVP} / \mathrm{CA} /$ garlic and PVP/CA/glycerine mats were in 
Table 2 The $\mathrm{pH}$ of the composite nanofibrous mats, glycerine, deionized water, and garlic extract

\begin{tabular}{ll}
\hline Samples & $\mathrm{pH}$ \\
\hline PVP/CA & $3.70 \pm 0.11$ \\
PVP/CA/garlic & $3.96 \pm 0.13$ \\
PVP/CA/glycerine & $3.85 \pm 0.11$ \\
PVP/CA/glycerine/garlic & $4.01 \pm 0.07$ \\
Glycerine & $4.26 \pm 0.00$ \\
Deionized water & $6.09 \pm 0.02$ \\
Garlic extract & $6.92 \pm 0.01$
\end{tabular}

the middle. The $\mathrm{pH}$ of the $\mathrm{PVP} / \mathrm{CA} /$ garlic mat was slightly higher since, experimentally, the garlic extract has a larger $\mathrm{pH}$ compared to glycerine. Therefore, it can be concluded that the composite nanofibrous mat with an encapsulated garlic extract has a pH slightly below that of healthy skin, which is conducive for hindering the growth of bacteria.

\subsection{Tensile properties of the nanofibrous mats}

A set of graphs and a table providing the relationship between the stress and strain for all the mats as well as the average ultimate tensile strength and the Young's modulus of the mats are presented (Fig. 7 and Table 3). The addition of garlic into the composite PVP/CA fibres, however, significantly increased both the Young's modulus and the ultimate tensile strength (UTS), indicating that the fibres had become less flexible. The reason for this substantial increase was the reduction in the fibre diameter. For a given mass of a nanofibrous mat, the reduction in the diameter generally increases the Young's modulus and UTS of the fibre mat because a larger number of parallel chains can result in a higher number of bonds. ${ }^{81}$ Thus, since the diameter of the $\mathrm{PVP} / \mathrm{CA} /$ garlic composite fibres was smaller than that of the PVP/CA composite fibres, the Young's modulus and UTS of PVP/CA/garlic were higher. Nevertheless, the

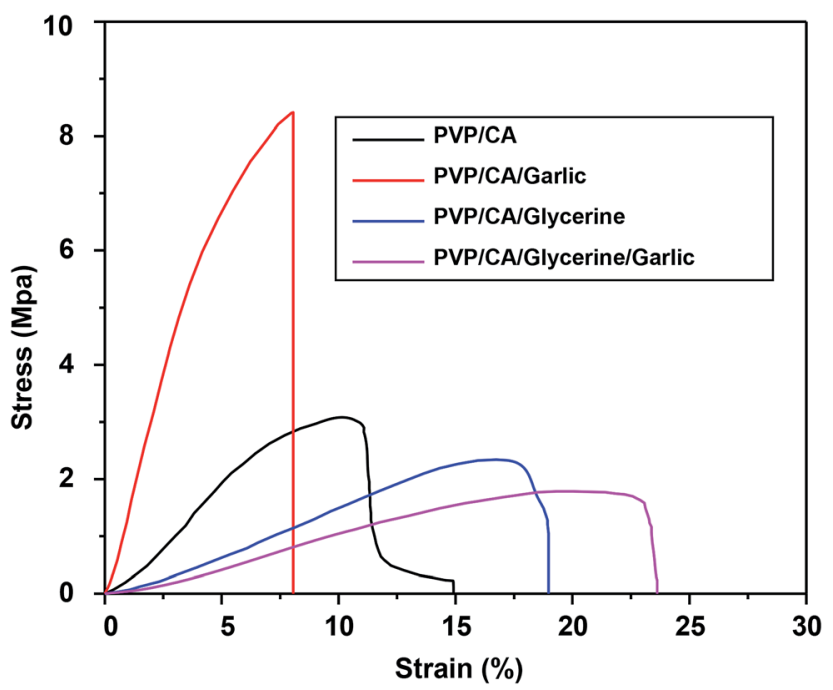

Fig. 7 The graphs describing the relation between stress and strain for all the fibrous mats.
Table 3 The Young's modulus and the ultimate tensile strength for all the composite mats

\begin{tabular}{lcl}
\hline Samples & Young's modulus (MPa) & $\begin{array}{l}\text { Ultimate tensile } \\
\text { strength }(\mathrm{MPa})\end{array}$ \\
\hline PVP/CA & $51.75 \pm 2.57$ & $2.94 \pm 0.35$ \\
PVP/CA/garlic & $161.23 \pm 18.50$ & $8.20 \pm 1.58$ \\
PVP/CA/glycerine & $19.04 \pm 1.95$ & $2.43 \pm 0.38$ \\
PVP/CA/glycerine/garlic & $14.6 \pm 2.23$ & $2.05 \pm 0.50$
\end{tabular}

addition of glycerine successfully decreased the Young's modulus and UTS significantly, as observed for the PVP/CA/ glycerine and $\mathrm{PVP} / \mathrm{CA} /$ glycerine/garlic fibrous mats, due to the plasticization of the fibres by glycerine, causing the fibrous mats to be more flexible. ${ }^{82}$ Microscopically, the reduction in Young's modulus was caused by the formation of hydrogen bonds between glycerine and the polymer chains; hence, the attraction between the polymer chains weakened, while there was easier sliding between the polymer chains once the chains were greased by glycerine.$^{83}$ On the other hand, the reduction in UTS by the addition of glycerine was caused by the highly amorphous structure of fibres. ${ }^{82}$

\subsection{Antibacterial activity of the garlic extract and the composite fibres}

The antibacterial assay test of the garlic extract was conducted using the microdilution method. The turbidity of the MHB media after 24 hours of incubation from column 2 to column 12 decreased as the concentration of the garlic extract increased (Fig. S2 $\dagger$ ). Column 1 was the negative control, where there was only the growth medium inside; therefore, the solution was clear. It was indicated that MIC for the Pseudomonas aeruginosa bacteria was $6.25 \%(\mathrm{v} / \mathrm{v})$, while for the Staphylococcus aureus bacteria, it was $12.5 \%(\mathrm{v} / \mathrm{v})$ as the solutions were quite clear for these concentrations. The columns related to these two concentrations are shown inside the red rectangles.

Afterwards, the minimal bactericidal concentrations (MBCs) were determined by inspecting the growth of bacteria when one dose of the MHB solution was scratched onto MHA in a Petri dish and incubated for 24 hours. The results confirmed that there was no bacterial growth at the zone scratched by the MHB solution at the tenth column, which represented the garlic concentration of $25 \%(\mathrm{v} / \mathrm{v})$ for both the types of bacteria (Fig. S3†). The microdilution method is similar to the broth dilution method and it has already been tested for an aqueous garlic extract. ${ }^{84}$ From a previous experiment, the MBC and MIC values of the garlic extract were similar to the MBC and MIC values of garlic juice when tested against Pseudomonas aeruginosa using the same method although the results differed for Staphylococcus aureus. ${ }^{85}$

The antibacterial activity of the composite nanofibres PVP/ $\mathrm{CA}, \mathrm{PVP} / \mathrm{CA} /$ glycerine, $\mathrm{PVP} / \mathrm{CA} /$ garlic, and $\mathrm{PVP} / \mathrm{CA} /$ glycerine/ garlic was investigated using total plate count (TPC). Each mat was cut into circles with a diameter of around $20 \mathrm{~mm}$ and then weighed (Table 4). Each type of bacteria was tested on the circular cuts. After 24 hours of incubation, the zones of 
Table 4 The weight of the circular cut of the mats
Weight (mg)

Composite nanofibres

S. aureus

13.9

PVP/CA

$\mathrm{PVP} / \mathrm{CA} /$ garlic

$\mathrm{PVP} / \mathrm{CA} /$ glycerine

$\mathrm{PVP} / \mathrm{CA} /$ glycerine/garlic

8.8

42.8

17.3

P. aeruginosa

15.9

14.1

46.6

21.7 inhibition against Pseudomonas aeruginosa were clearly formed around the PVP/CA/glycerine and PVP/CA/glycerine/garlic mats, while it was not so well defined for the PVP/CA/garlic mat (Fig. 8). The reason might be that the weight of the PVP/CA/ garlic circular cut was not sufficient to provide significant antibacterial activity. This was further confirmed by the fact that no zone of inhibition appeared for the mats in contact with Staphylococcus aureus.

As the weight of PVP/CA/garlic was too low, the zone of inhibition was so small that it could not be observed clearly from the digital image alone. To confirm whether the mat possessed antibacterial activity, a further test was done. The total count plate method was carried out by taking the agar above each mat, swabbing into an MHA, and then incubating for another 24 hours.

After incubation, the bacterial colonies for the control and for all the mats were observed (Fig. S4 and S5 $\dagger$ ). The results of the test can be used to observe the inhibition capability of the mat towards bacteria. For $\log _{10}$ reduction $/ \mathrm{cm}^{2}$, the antibacterial test results are as follows: for Pseudomonas aeruginosa, the mat with the highest ability to inhibit the growth of bacteria was $\mathrm{PVP} / \mathrm{CA} /$ glycerine/garlic, followed closely by PVP/CA/garlic and
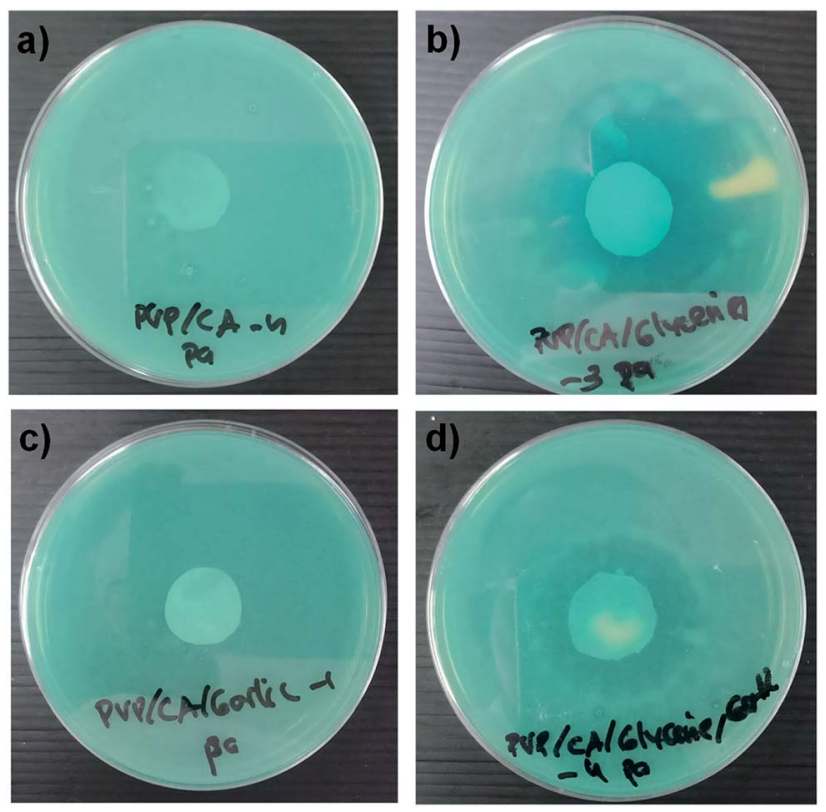

Fig. 8 Images of the zones of inhibition against Pseudomonas aeruginosa observed after $24 \mathrm{~h}$ contact of (a) PVP/CA, (b) PVP/CA/glycerine, (c) PVP/CA/garlic, and (d) PVP/CA/glycerine/garlic. then PVP/CA/glycerine, while the PVP/CA mat did not show significant antibacterial activity (Table 5). For the Staphylococcus aureus bacteria, the $\mathrm{PVP} / \mathrm{CA} /$ garlic mat had larger antibacterial activity than the $\mathrm{PVP} / \mathrm{CA} /$ glycerine/garlic mat. The antibacterial activity of the mats can be confirmed by the smaller number of the bacterial colonies formed compared to the control. It was also found that for all the fibres, $\log _{10}$ reduction $/ \mathrm{cm}^{2}$ of the mats was smaller against Staphylococcus aureus, which might be due to the weight of the fibres being lesser. When the weight of the mat was put into consideration, some significant changes occurred in the result. The antibacterial activity of the PVP/CA/ garlic nanofibrous mat was found to be very powerful against both Staphylococcus aureus and Pseudomonas aeruginosa. On the end of the spectrum, the PVP/CA/glycerine fibres had the lowest antibacterial activity for both the types of bacteria. Thus, glycerine acted as the antithesis of garlic as the antibacterial agent, which was also reported in a previous experiment. ${ }^{53}$ Although no garlic was included, the PVP/CA fibres still possessed antibacterial activity due to their acidic nature. When tested against Staphylococcus aureus, PVP/CA/glycerine/garlic exhibited lower antibacterial activity than PVP/CA due to the low antibacterial action of glycerine. The antibacterial activity of glycerine was slightly improved when tested against Pseudomonas aeruginosa; therefore, the PVP/CA/glycerine/garlic fibres had higher antibacterial activity, which was even higher than that of PVP/CA. At this point, the antibacterial action of garlic exceeded the reverse action of glycerine. Overall, it can be concluded that garlic was the main contributor to the antibacterial activity of the fibres, while glycerine worked in the opposite way. The acidity of the fibres still played an important role, as shown by the antibacterial activity of PVP/CA, which coincidentally exhibited the lowest $\mathrm{pH}$, as proven in the acidity test.

When compared to some commercial wound dressings, the fibre mats containing garlic have larger $\log _{10}$ reduction $/ \mathrm{cm}^{2}$ than the commercial wound dressing Mepilex® $\mathrm{Ag}\left(\right.$ at $0.2 \mathrm{~cm}^{-2}$ ) when tested against Staphylococcus aureus. For the antibacterial testing against Pseudomonas aeruginosa, the garlic-loaded fibres showed better antibacterial activity compared to PolyMem® $\mathrm{Ag}$ (at $0.1 \mathrm{~cm}^{-2}$ ). It must be admitted, however, that the garlicloaded fibres were still below the much superior Aquacel ${ }^{\circledR} \mathrm{Ag}$ dressing for both the types of bacteria. The large antibacterial activity of Aquacel ${ }^{\circledR} \mathrm{Ag}$ is related to its rapid release of silver due to its non-woven fabric substrates. It is then possible to acquire the level of the antibacterial activity of Aquacel ${ }^{\circledR} \mathrm{Ag}$ by increasing the mass of the mat since the structures are similar. ${ }^{\mathbf{8 6}}$

\subsection{In vitro release study}

A release study was conducted to examine the release pattern of glycerine and garlic from the fibres, which is a significant aspect of the drug delivery system and thus can affect the antibacterial activity of the composite fibres. ${ }^{47}$ The release of a drug is affected by many parameters; hence, predicting the release rate is quite complicated. The parameters are the structure of the fibres, the properties and the amount of the loaded drug, the wetting and the solubility of the carrier and the existence of additional excipients or treatments during the synthesis of 
Table 5 The number of bacterial colonies formed after being incubated for 24 hours

\begin{tabular}{|c|c|c|c|c|c|c|}
\hline \multirow[b]{2}{*}{ Composite nanofibres } & \multicolumn{2}{|c|}{$\begin{array}{l}\text { Bacterial colonies }\left(\mathrm{cfu} \mathrm{mL}^{-1}\right) \\
\text { after } 24 \text { hours incubation }\end{array}$} & \multicolumn{2}{|c|}{$\log _{10}$ reduction $/ \mathrm{cm}^{2}$} & \multicolumn{2}{|c|}{$\begin{array}{l}\text { Antibacterial activity of } \\
\text { nanofibres (\% per gram) }\end{array}$} \\
\hline & S. aureus & P. aeruginosa & S. aureus & P. aeruginosa & S. aureus & P. aeruginosa \\
\hline $\mathrm{PVP} / \mathrm{CA}$ & 13.74817 & 12.25355 & 0.4636 & 0.5406 & 6.89 & 7.66 \\
\hline PVP/CA/garlic & 13.27676 & 11.07088 & 0.6136 & 0.9170 & 14.41 & 14.46 \\
\hline PVP/CA/glycerine & 13.91638 & 11.07995 & 0.4100 & 0.9141 & 1.98 & 4.41 \\
\hline
\end{tabular}

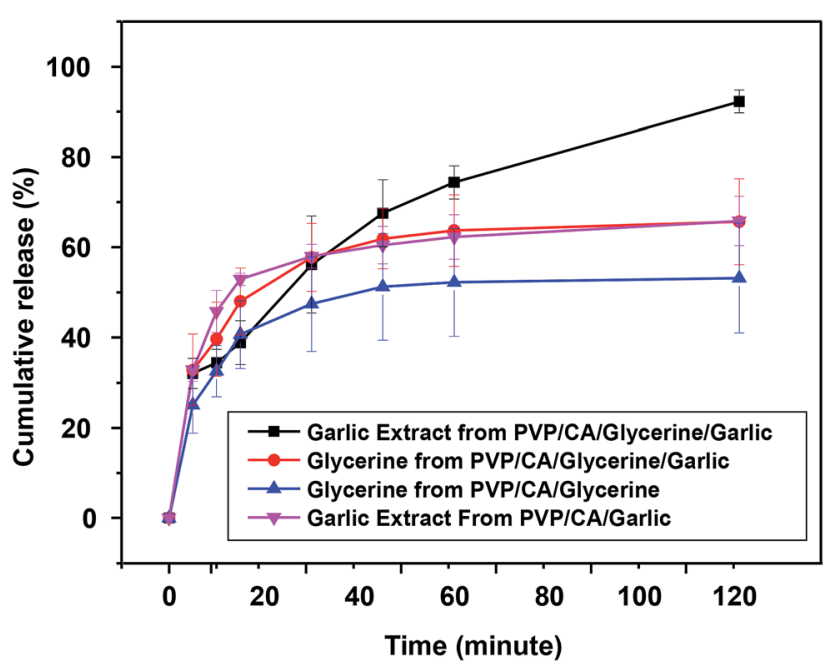

Fig. 9 The release patterns of garlic extract from the composite fibres of PVP/CA/glycerine/garlic and PVP/CA/garlic and also for glycerine from PVP/CA/glycerine/garlic and PVP/CA/glycerine.

nanofibres. From the interactions among the parameters, the types of release can thus be categorized as immediate release, sustained release with initial burst release, and sustained release. ${ }^{87}$ In immediate release, the drug is released within a short time, typically hours, with the drug mainly located on the surface of the fibres. ${ }^{88}$ On the other hand, sustained release is basically achieved through a complex combination of processes, including the diffusion of the drug through the fibres, polymer degradation in the buffer solution, partition between the drug and the polymer, and the dissolution of the drug in the buffer solution, in which the release rate of the drug can be steady for days. ${ }^{89}$ There is a very rapid release of the drug, where all the drug content is released within less than one hour; this is usually called burst release. The porous structure and the hydrophilic nature of the carrier are suspected to be the reason behind burst release. ${ }^{90}$ In this experiment, PBS was at the physiological $\mathrm{pH}$ of 7.4 , which is the average $\mathrm{pH}$ of the human body. While the release pattern was not identical to sustained release, it was clearly not burst release either. The pattern of release inclined towards immediate release at different rates between the fibres. As depicted, the release rate of garlic and glycerine was larger in the fibrous $\mathrm{PVP} / \mathrm{CA} /$ glycerine/garlic mat compared to the release rates of glycerine and garlic extract from PVP/CA/glycerine and PVP/CA/garlic (Fig. 9). The release rate of garlic extract from the fibrous $\mathrm{PVP} / \mathrm{CA} /$ glycerine/garlic mat was the fastest among all. The large rate of release of glycerine and garlic extract from $\mathrm{PVP} / \mathrm{CA} /$ glycerine/garlic was expected due to the larger diameter of fibres as compared to that for $\mathrm{PVP} / \mathrm{CA} /$ glycerine and $\mathrm{PVP} / \mathrm{CA} /$ garlic. The fibres with a small diameter generally have a denser structure, making the medium harder to penetrate; therefore, there is less interaction between the fibres and PBS solution. ${ }^{91}$ This result also agreed with a previous finding, in which glycerine could increase the release rate of the drugs by expanding the channel of release when immersed in solution. ${ }^{92}$ The release of glycerine was found to be relatively slower compared to that of garlic. This might be caused by the adhesive nature of glycerine, which was confirmed by the low swelling degree of the PVP/CA/glycerine/ garlic and PVP/CA/glycerine fibres. The release rate of the active agent, i.e., the garlic extract was slower compared to that in a previous experiment, where PVP was the sole backbone of the fibres. ${ }^{91}$ The blend of CA with PVP clearly reduced the release rate since $\mathrm{CA}$ is insoluble in water, which is the main ingredient of the PBS solution. The erosion of the composite fibres was thus slower. For all the cases, one-hundred percent release was not fully achieved within the first 120 minutes. However, more than $60 \%$ of the garlic extract was released within the measured time and therefore, the amount of the garlic extract released should already be significant to inhibit the growth of bacteria, as proven by the result of the antibacterial test. For certain applications that require immediate release of drugs, the composite fibres of $\mathrm{PVP} / \mathrm{CA} /$ glycerine/garlic or PVP/CA/garlic should be appropriate.

\section{Conclusion}

We successfully prepared different combinations of composite fibres involving glycerine and garlic extracts with PVP and CA as the building blocks using the electrospinning method. Beadfree fibres of size under one $\mu \mathrm{m}$, confirmed from their SEM images, showed adequate composition of materials in the precursor solutions. Glycerine and the garlic extract were present in the composite fibres, as indicated in the FTIR spectra. The composite fibres PVP/CA/glycerine/garlic and PVP/ $\mathrm{CA} /$ garlic had maximum swelling degrees above 100\%, while 
the existence of glycerine significantly reduced the degree of swelling. The $\mathrm{pH}$ level of the fibres ranged from 3.7 to 4.0 with some difference due to the content of acetic acid in the precursor solution. The addition of glycerine successfully decreased the Young's modulus and UTS of the composite fibres. The antibacterial activity of the garlic extract after being encapsulated in the fibres was still maintained, as proven from the in vitro antibacterial test. The results of the drug release test proved that the release pattern of the garlic extract and glycerine was that of immediate release.

\section{Conflicts of interest}

There are no conflicts to declare.

\section{Acknowledgements}

This research was financially supported by the Directorate of Research and Community Engagement, Ministry of Research, Technology, and Higher Education, the Republic of Indonesia under the University's Excellence Applied Research (PTUPT) Grant in the fiscal years of 2018-2019 and the World Class Research Grant 2019, and the Dissertation Research 2019.

\section{References}

1 D. Wallock-Richards, Garlic Revisit, PLoS One, 2014, 13, 1-4.

2 K. Prasad, V. A. Laxdal, M. Yu and B. L. Raney, Mol. Cell. Biochem., 1995, 148, 183-189.

3 M. Focke, A. Feld and H. K. Lichtenthaler, FEBS Lett., 1990, 261, 106-108.

4 M. Thomson and M. Ali, Curr. Cancer Drug Targets, 2003, 3, 67-81.

5 M. Corzo-Martínez, N. Corzo and M. Villamiel, Trends Food Sci. Technol., 2007, 18, 609-625.

6 W. A. Sarhan, H. M. E. Azzazy and I. M. El-Sherbiny, ACS Appl. Mater. Interfaces, 2016, 8, 6379-6390.

7 K. F. A. Ross, J. Cell Sci., 1957, 98, 435-454.

8 Y. Qing, L. Cheng, R. Li, G. Liu, Y. Zhang, X. Tang, J. Wang, H. Liu and Y. Qin, Int. J. Nanomed., 2018, 13, 3311-3327.

9 A. K. Chatterjee, R. Chakraborty and T. Basu, Nanotechnology, 2014, 25, 135101.

10 Y. Cui, Y. Zhao, Y. Tian, W. Zhang, X. Lü and X. Jiang, Biomaterials, 2012, 33, 2327-2333.

11 E. Abiy and A. Berhe, Journal of Infectious Diseases and Treatment, 2016, 2, 2.

12 J. C. Harris, S. L. Cottrell, S. Plummer and D. Lloyd, Appl. Microbiol. Biotechnol., 2001, 57, 282-286.

13 Y. Liu, K. Ai and L. Lu, Chem. Rev., 2014, 114, 5057-5115.

14 M. Liu, G. Zeng, K. Wang, Q. Wan, L. Tao, X. Zhang and Y. Wei, Nanoscale, 2016, 8, 16819-16840.

15 G. Zeng, L. Huang, Q. Huang, M. Liu, D. Xu, H. Huang, Z. Yang, F. Deng, X. Zhang and Y. Wei, Appl. Surf. Sci., 2018, 459, 588-595.

16 T. J. MacDonald, K. Wu, S. K. Sehmi, S. Noimark, W. J. Peveler, H. Du Toit, N. H. Voelcker, E. Allan,
A. J. MacRobert, A. Gavriilidis and I. P. Parkin, Sci. Rep., 2016, 6, 39272.

17 P. S. Harikumar, Int. J. Sci., 2016, 5, 83-90.

18 Q. Huang, M. Liu, L. Mao, D. Xu, G. Zeng, H. Huang, R. Jiang,

F. Deng, X. Zhang and Y. Wei, J. Colloid Interface Sci., 2017, 499, 170-179.

19 Q. Huang, M. Liu, J. Chen, Q. Wan, J. Tian, L. Huang, R. Jiang, Y. Wen, X. Zhang and Y. Wei, Appl. Surf. Sci., 2017, 419, 35-44.

20 X. Zhang, Q. Huang, M. Liu, J. Tian, G. Zeng, Z. Li, K. Wang, Q. Zhang, Q. Wan, F. Deng and Y. Wei, Appl. Surf. Sci., 2015, 343, 19-27.

21 X. Zhang, Q. Huang, F. Deng, H. Huang, Q. Wan, M. Liu and Y. Wei, Applied Materials Today, 2017, 7, 222-228.

22 Y. Shi, R. Jiang, M. Liu, L. Fu, G. Zeng, Q. Wan, L. Mao, F. Deng, X. Zhang and Y. Wei, Mater. Sci. Eng., C, 2017, 77, 972-977.

23 M. Liu, J. Ji, X. Zhang, X. Zhang, B. Yang, F. Deng, Z. Li, K. Wang, Y. Yang and Y. Wei, J. Mater. Chem. B, 2015, 3, 3476-3482.

24 Y. Wang and H. Yin, Talanta, 2019, 200, 432-442.

25 Y. Shi, M. Liu, F. Deng, G. Zeng, Q. Wan, X. Zhang and Y. Wei, J. Mater. Chem. B, 2017, 5, 194-206.

26 R. M. Tripathi and S. J. Chung, J. Microbiol. Methods, 2019, 157, 65-80.

27 L. Huang, M. Liu, H. Huang, Y. Wen, X. Zhang and Y. Wei, Biomacromolecules, 2018, 19, 1858-1868.

28 Y. Qu, F. He, C. Yu, X. Liang, D. Liang, L. Ma, Q. Zhang, J. Lv and J. Wu, Mater. Sci. Eng., C, 2018, 90, 764-780.

29 S. Gopi, P. Balakrishnan, D. Chandradhara, D. Poovathankandy and S. Thomas, Mater. Today Chem., 2019, 13, 59-78.

30 M. R. MacEwan, S. MacEwan, T. R. Kovacs and J. Batts, Cureus, 2017, 9, 1-12.

31 A. Podgórski, A. Bałazy and L. Gradoń, Chem. Eng. Sci., 2006, 61, 6804-6815.

32 A. Zulfi, M. M. Munir, D. A. Hapidin, A. Rajak, D. Edikresnha, F. Iskandar and K. Khairurrijal, Mater. Res. Express, 2018, 5, 035049.

33 H. Yoshimoto, Y. M. Shin, H. Terai and J. P. Vacanti, Biomaterials, 2003, 24, 2077-2082.

34 X. Y. Dai, W. Nie, Y. C. Wang, Y. Shen, Y. Li and S. J. Gan, J. Mater. Sci.: Mater. Med., 2012, 23, 2709-2716.

35 S. Ramakrishna, K. Fujihara, W.-E. Teo, T.-C. Lim and Z. Ma, An Introduction to Electrospinning And Nanofibres, World Scientific Publishing, Singapore, 2005.

36 X. Shen, D. Yu, L. Zhu, C. Branford-White, K. White and N. P. Chatterton, Int. J. Pharm., 2011, 408, 200-207.

37 K. H. Hong, Polym. Eng. Sci., 2007, 47, 43-49.

38 N. Mansor, H. J. Herng, S. J. Samsudin, S. Sufian and Y. Uemura, J. Med. Bioeng., 2016, 5, 24-27.

39 H. Fujisawa, K. Suma, K. Origuchi, T. Seki and T. Ariga, Biosci., Biotechnol., Biochem., 2008, 72, 2877-2883.

40 I. Sriyanti, D. Edikresnha, A. Rahma, M. M. Munir, H. Rachmawati and K. Khairurrijal, J. Nanomater., 2017, 2017, 1-11. 
41 R. Konwarh, N. Karak and M. Misra, Biotechnol. Adv., 2013, 31, 421-437.

42 O. Z. Higa, S. O. Rogero, L. D. B. Machado, M. B. Mathor and A. B. Lugão, Radiat. Phys. Chem., 1999, 55, 705-707.

43 H. Kesici Güler, F. Cengiz Çallıŏ̆lu and E. Sesli Çetin, J. Text. Inst., 2018, 110, 302-310.

44 S. Huang, L. Zhou, M. C. Li, Q. Wu, Y. Kojima and D. Zhou, Materials, 2016, 9, 523.

45 M. Ignatova, N. Manolova and I. Rashkov, Eur. Polym. J., 2007, 43, 1112-1122.

46 S. Suganya, T. Senthil Ram, B. S. Lakshmi and V. R. Giridev, J. Appl. Polym. Sci., 2011, 121, 2893-2899.

47 I. Sriyanti, D. Edikresnha, A. Rahma, M. M. Munir, H. Rachmawati and K. Khairurrijal, Int. J. Nanomed., 2018, 13, 4927-4941.

48 S. Fitzpatrick, J. F. McCabe, C. R. Petts and S. W. Booth, Int. J. Pharm., 2002, 246, 143-151.

49 M. McGath, S. Jordan-Mowery, M. Pollei, S. Heslip and J. Baty, Restaurator, 2015, 36, 333-365.

50 S. W. Kim, S. O. Han, I. N. Sim, J. Y. Cheon and W. H. Park, J. Nanomater., 2015, 2015, 1-8.

51 M. M. Castillo-Ortega, J. Romero-García, F. Rodríguez, A. A. Nájera-Luna and P. Herrera-Franco, J. Appl. Polym. Sci., 2010, 116, 1873-1878.

52 Y. Shi, Z. Wei, H. Zhao, T. Liu, A. Dong and J. Zhang, J. Nanosci. Nanotechnol., 2013, 13, 3855-3863.

53 N. Thaddeus, E. Francis, O. Jane, A. Obumneme and E. Okechukwu, Asian Pac. J. Trop. Med., 2018, 11, 222-226.

54 D. Szymanowska-PowaŁowska, Electron. J. Biotechnol., 2015, 18, 128-133.

55 L. Vogt, L. Liverani, J. Roether and A. Boccaccini, Nanomaterials, 2018, 8, 150.

56 M. Kharaziha, M. Nikkhah, S. R. Shin, N. Annabi, N. Masoumi, A. K. Gaharwar, G. Camci-Unal and A. Khademhosseini, Biomaterials, 2013, 34, 6355-6366.

57 H. Fujisawa, K. Suma, K. Origuchi, H. Kumagai, T. Seki and T. Ariga, J. Agric. Food Chem., 2008, 56, 4229-4235.

58 D. Parsons and P. Bowler, Wounds, 2005, 17, 222-232.

59 Y. Rukayadi, K. Lee, S. Han, D. Yong and J. K. Hwang, Antimicrob. Agents Chemother., 2009, 53, 4529-4532.

60 P. O. Rujitanaroj, N. Pimpha and P. Supaphol, J. Appl. Polym. Sci., 2010, 116, 1967-1976.

61 V. L. Oliveira, C. Morais, K. Servat, T. W. Napporn, G. Tremiliosi-Filho and K. B. Kokoh, J. Electroanal. Chem., 2013, 703, 56-62.

62 M. Araújo, R. Viveiros, T. R. Correia, I. J. Correia, V. D. B. Bonifácio, T. Casimiro and A. Aguiar-Ricardo, Int. J. Pharm., 2014, 469, 140-145.

63 A. G. M. Ferreira, A. P. V. Egas, I. M. A. Fonseca, A. C. Costa, D. C. Abreu and L. Q. Lobo, J. Chem. Thermodyn., 2017, 113, 162-182.

64 V. B. Mintsev and V. E. Fortov, Laser Part. Beams, 2015, 33, 41-50.

65 F. Bandarkar, I. S. Khattab, F. Martinez, M. Khoubnasabjafari, S. Vahdati and A. Jouyban, Phys. Chem. Liq., 2015, 53, 104-116.
66 C. Arneodo, A. Baszkin, J. P. Benoit, R. Fellous and C. Thies, Colloids Surf., 1988, 34, 159-169.

67 J. Matulevicius, L. Kliucininkas, T. Prasauskas, D. Buivydiene and D. Martuzevicius, J. Aerosol Sci., 2016, 92, 27-37.

68 P. Pusporini, D. Edikresnha, I. Sriyanti, T. Suciati, M. M. Munir and K. Khairurrijal, Mater. Res. Express, 2018, 5, 054001.

69 A. Sawitri, M. M. Munir, D. Edikresnha, A. Sandi, A. Fauzi, A. Rajak, D. Natalia and K. Khairurrijal, Mater. Res. Express, 2018, 5, 054003.

70 S.-H. Tan, R. Inai, M. Kotaki and S. Ramakrishna, Polymer, 2005, 46, 6128-6134.

71 M. M. Munir, A. B. Suryamas, F. Iskandar and K. Okuyama, Polymer, 2009, 50, 4935-4943.

72 P. Fei, L. Liao, B. Cheng and J. Song, Anal. Methods, 2017, 9, 6194-6201.

73 K. M. Ahmed, M. P. McLeod, J. Nézivar and A. W. Giuliani, Spectroscopy, 2010, 24, 601-608.

74 B. J. Divya, B. Suman, M. Venkataswamy and K. Thyagaraju, Int. J. Curr. Pharm. Res., 2017, 9, 40-43.

75 H. Li, F. Cheng, S. Gao, Z. Wu, L. Dong, S. Lin, Z. Luo and X. Li, J. Appl. Polym. Sci., 2017, 134, 45441.

76 J. Drelich, E. Chibowski, D. D. Meng and K. Terpilowski, Soft Matter, 2011, 7, 9804-9828.

77 J. Yin, H. Fan and J. Zhou, Desalin. Water Treat., 2016, 57, 10572-10584.

78 T. Maver, S. Hribernik, T. Mohan, D. M. Smrke, U. Maver and K. Stana-Kleinschek, RSC Adv., 2015, 5, 77873-77884.

79 L. A. Schneider, A. Korber, S. Grabbe and J. Dissemond, Arch. Dermatol. Res., 2007, 298, 413-420.

80 X. Yang, K. Wang, H. Wang, J. Zhang, L. Tang and Z. Mao, RSC Adv., 2016, 6, 57902-57909.

81 J. Yao, C. Baastiansen and T. Peijs, Fibers, 2014, 2, 158-187. 82 H. Zhang, L. Deng, M. Yang, S. Min, L. Yang and L. Zhu, Int. J. Mol. Sci., 2011, 12, 3170-3181.

83 M. Z. B. Yunos and W. A. W. A. Rahman, J. Appl. Sci., 2011, 11, 2456-2459.

84 S. K. Saha, S. Saha, S. M. Akhter, S. Khatun, M. M. Islam and P. Roy, Mymensingh Med. J., 2016, 25, 477-484.

85 S. Yadav, N. Trivedi and J. Bhatt, AYU (An International Quarterly Journal of Research in Ayurveda), 2016, 36, 203.

86 S. Yunoki, M. Kohta, Y. Ohyabu and T. Iwasaki, Plast. Surg. Nurs., 2015, 35, 203-211.

87 I. Sebe, P. Szabó, B. Kállai-Szabó and R. Zelkó, Int. J. Pharm., 2015, 494, 516-530.

88 H. S. Yoo, T. G. Kim and T. G. Park, Adv. Drug Deliv. Rev., 2009, 61, 1033-1042.

89 S. F. Chou, D. Carson and K. A. Woodrow, J. Control. Release, 2015, 220, 584-591.

90 X. Huang and C. S. Brazel, J. Control. Release, 2001, 73, 121136.

91 A. Rahma, M. M. Munir, K. Khairurrijal, A. Prasetyo, V. Suendo and H. Rachmawati, Biol. Pharm. Bull., 2016, 39, 163-173.

92 Y. Cai, J. Che, M. Yuan, X. Shi, W. Chen and W. E. Yuan, Exp. Ther. Med., 2016, 12, 2039-2044. 